\title{
OLIVEIRA, João Pacheco de; COHN, Clarice (orgs.). 2014. Belo Monte e a questão indígena. Brasília/DF: ABA. 337 p.
}

Alessandro Roberto

Oliveira (UFG)
"Belo Monte e a questão indígena" é um dossiê sobre a construção da hidroelétrica de Belo Monte e suas repercussões para as populações indígenas que vivem na região do médio rio Xingu, no Estado do Pará. O volume organizado pelos antropólogos Clarice Cohn e João Pacheco de Oliveira resulta de uma série de atividades, manifestações e discussões públicas sobre o tema realizadas pela Associação Brasileira de Antropologia - ABA, através de sua Comissão de Assuntos Indígenas - CAl, desde 2009 até a publicação do e-book em 2014, que pode ser baixado no site da entidade.

O objetivo do dossiê é oferecer à comunidade antropológica e à opinião pública uma compreensão crítica, abrangente e aprofundada sobre este grande empreendimento. Para isso, a publicação reuniu especialistas de diversas áreas do conhecimento, que abordam este processo de diferentes prismas, que vão muito além da polaridade simplista entre promotores do desenvolvimento do país e defensores do meio ambiente. O livro começou a ser montado em 2010, ano em que foi realizado o leilão para a construção da usina, e foi publicado em 2014. Produzido em meio aos seus desdobramentos, retrata a história recente do processo de licenciamento ambiental e os impactos dessa grande obra vividos pelos povos indígenas em suas terras e também em Altamira. Neste sentido, o livro traz subsídios para a reflexão sobre questões que devem mobilizar o debate público no Brasil nos próximos anos, dentre elas as formas de promover o desenvolvimento na Amazônia e a garantia dos direitos das populações que vivem na região. Neste cenário ganha centralidade o debate sobre o sentido e a operacionalização do direito à Consulta Livre, Prévia e Informada no país, previsto na Convenção Internacional do Trabalho 169 (OIT) e incorporado à legislação brasileira.

Belo Monte é um projeto de engenharia e um processo político que tem raízes no período da ditatura brasileira. O projeto inicialmente denominado "Kararaô" - termo que de saída irritou os Kayapó por se tratar de um "nome 
de guerra" e por ser um "sobrenome" de um grupo de parentes situados no rio Iriri - não avançou nas últimas décadas, em grande medida por causa mobilização dos povos indígenas e seus aliados ambientalistas no Brasil e no exterior, articulação que ganhou notoriedade internacional com o grande encontro dos povos indígenas realizado em Altamira em 1989 e que influenciou decisões como a do Banco Mundial de não aportar recursos para financiamento da obra à época.

Nas últimas duas décadas a proposta de construção da usina de Kararô mudou de nome e de projeto de engenharia. Rebatizado de Belo Monte, o projeto foi remodelado e, ao invés da construção de um reservatório, como previsto originalmente, planejou-se a mudança do curso do rio para construir uma hidroelétrica por fio d'água, o que na prática significa realizar um desvio das águas do rio Xingu desde a barragem do Sítio Pimental até o município de Belo Monte, onde ficarão as turbinas principais. O impacto maior deixou de ser a inundação e tornou-se a seca de rios que banham terras indígenas. Com esta mudança de projeto, povos que antes não estavam no raio de impactos diretos passaram a figurar como os principais atingidos pela obra.

O livro reúne vinte contribuições, distribuídas em três partes. A primeira, intitulada "uma visão geral", traz discussões sobre projetos de grande escala e seus vínculos com a expansão do sistema capitalista hegemônico, tratando de seus reflexos na aplicação dos instrumentos da política ambiental brasileira e sobre os direitos indígenas. Como aponta Marcelo Montaño logo no primeiro artigo, a falta de planejamento e o descaso com as questões ambientais e sociais são gritantes no caso de Belo Monte. Não é possível saber ao certo os custos da obra (em 2010 os valores oscilavam entre $R \$ 19,6$ bilhões na perspectiva do governo e $R$ \$ 30 bilhões nas estimativas de investidores); e os dados sobre a capacidade de geração de energia estimados para o empreendimento também não são claros (noticiava-se, em 2010, que a capacidade de Belo Monte é muito mais baixa que a da média das hidroelétricas existentes, além do que, na época de seca, garante-se apenas $40 \%$ dessa capacidade).

Gustavo Lins Ribeiro ressalta um aspecto comum a estes megaprojetos: a ambiguidade jurídica. O Estado, ainda que presente, omite-se deliberadamente de suas diversas obrigações normais, com vistas a não colocar em risco o ritmo destas iniciativas. Este quadro de obscuridade jurídica é terreno fértil para a geração de conflitos e isso fica claro nas contribuições que se seguem. Jane Felipe Beltrão, Assis da Costa Oliveira e Felício Pontes Jr. demostram como estes embates se deram em torno dos "significados do direito à consulta" que marcam negativamente o processo de construção de Belo Monte. Biviany Rojas descreve o percurso de "viabilização" da usina através do descumprimento sistemático das condicionantes socioambientais e suas consequências para o enfraquecimento do sistema de licenciamento ambiental, de seus mecanismos de monitoramento, fiscalização e cobrança. Em outra frente, Jane Felipe Beltrão, Helena Palmquist e Paulo César Beltrão Rabelo analisam a atuação do Ministério Público Federal na defesa dos direitos indígenas neste campo minado. À luz de princípios constitucionais e estatutos legais vigentes, os autores analisam as ações do MPF e seus trâmites no judiciário entre 2006 e 2011. Já William H. Fisher compara os diferentes momentos históricos da resistência indígena e procura responder por que indígenas e aliados não estão repetindo agora o mesmo sucesso do fim dos anos 1980, quando conseguiram bloquear o projeto "Kararaô". Alfredo Wagner e Rosa Elizabeth Acevedo Marin analisam mobilizações políticas 
mais recentes de indígenas, pescadores e ribeirinhos, abordando os espaços das audiências públicas nas quais os estudos de impacto ambiental foram apresentados a eles e suas narrativas sobre todo o processo. Oswaldo Sevá Filho fecha a primeira parte analisando a "sinfonia maligna" que compõe a história da usina, revelando os fios condutores da acumulação capitalista que sustentam o projeto e as armadilhas do debate sobre oferta de energia "limpa e renovável".

A segunda parte "Belo Monte e a questão indígena" é um mergulho no contexto regional dos povos indígenas na cidade de Altamira e em suas terras e apresenta como alguns deles estão tentando compreender todo este processo. Mayra Pascuet e Mariana Favero apresentam dados sobre os citadinos. Marlinda Melo Patrício reflete sobre a situação dos Arara da Volta Grande do Xingu - VGX, que têm no rio sua principal fonte de alimentação e de acesso à cidade de Altamira e estão vivendo uma série de transformações econômicas, sociais, políticas e culturais com a chegada da obra. Assim também estão os Juruna-Yudjá, situados na Terra Indígena Paquiçamba, também na VGX, que é o locus da construção de diques, canais de adução e de derivação, reservatório dos canais, vertedouros, casas de força e dutos da usina, como mostra Maria Elisa Guedes Vieira. O território deles será fracionado e eles passarão a viver em uma ilha, perdendo a ligação terrestre com a construção dos canais.

Já os Xikrin, um dos dois grupos Kayapó, ou Mebengokré, como se referem a si mesmos, que vivem às margens do rio Bacajá, que flui para a VGX, vêm, desde 2009, insistindo em que a vazão reduzida do Xingu irá afetar o Bacajá, causando seca e a morte dos peixes e da caça. A obra vai dificultar o acesso à cidade, além de aumentar a ocorrência de doenças, como eles já estão observando. Nesta nova conjuntura, os Xikrin - que são reconhecidos como um povo guerreiro - estão tendo que lidar com um grande leque de atores (empreendedor, MP, escritórios de consultoria, ONGs nacionais e internacionais) com quem estão aprendendo a se relacionar, dialogando, debatendo e confrontando. O drama trazido por Belo Monte é interpretado por Clarice Cohn como uma "rendição de guerra", na qual, assim como nas guerras internacionais, uma nação perde a autonomia decisória para outra que a ocupa.

O último texto da segunda parte apresenta a situação dos Arara do Laranjal, um povo de língua Carib, situado à margem do rio Iriri, afluente do Xingu. O contato "pacifico" dos Arara com os brancos é recente, consolidou-se apenas no início dos anos 1980. Para este povo, o cenário também é de grande confusão. As exigências externas por um "representante" arara criaram um palco de disputa entre os grupos domésticos que vem gerando conflitos internos, acusações de feitiçaria, roubos, descumprimento de regras e multiplicação das aldeias. Neste contexto, Eduardo Henrique Capeli Belezini pergunta: “Mas, afinal, quem é a Norte Energia Sociedade Anônima (NESA) para os Arara do Laranjal?", "Quem são esses que estão querendo construir uma barragem e dão em troca essa infinidade de coisas, desde barcos, motores, até produtos alimentares?"(: 288). Segundo o autor, a NESA tem sido percebida por eles como um parceiro da Fundação Nacional do Índio (FUNAI), intermediária no repasse de presentes aos indígenas, papel que os Arara querem suprimir, mantendo as ações do órgão indigenista restritas às atividades executadas antes do aparecimento da NESA. Aqui, mais uma vez, o que se percebe é um quadro de entendimentos confusos e de relações de troca altamente desequilibradas com a chegada de Belo Monte. 
A terceira parte: "Com a palavra, os indígenas" fecha o dossiê com textos de representantes de alguns dos povos impactados por Belo Monte que foram convidados a colaborar com o volume. Este bloco é composto de depoimentos, entrevistas, relatos, desabafos, análises sobre impactos culturais e uma carta dos homens da aldeia Bacajá traduzida para o português. Nesta seção o leitor entra em contato direto com as percepções indígenas sobre o empreendimento, tanto daqueles que moram na cidade quanto aqueles que vivem em torno da barragem. Estes textos foram produzidos em um momento especialmente complicado, quando estava em curso o chamado "Plano Emergencial" - que basicamente estabeleceu repasses financeiros mensais para as comunidades impactadas pela obra, o que acirrou muitos conflitos internos em virtude de listas de compras e, ainda mais, pelo papel dúbio das instituições envolvidas nesta etapa que antecedeu o Plano Básico Ambiental (PBA) propriamente dito.

Nesta parte os representantes indígenas refletem sobre as transformações que cada povo está vivendo diante de Belo Monte. São relatos comoventes e indignantes pela quantidade de injustiças que elencam. Eles trazem o dissabor de suas comunidades com a quantidade de promessas e condicionantes não cumpridas, as regularizações fundiárias que não ocorreram, os impactos do Plano Emergencial - através do qual, no dizer de José Carlos Arara: "FUNAI e NESA globalizaram as pessoas e algumas lideranças" (: 310$)$ promovendo o fluxo de dinheiro e objetos nas aldeias e o contrafluxo intenso de pessoas para a cidade.

Trata-se, como Sheyla Juruna define: de um "Belo Monte de violações..." ou, como frisa Ozimar Juruna "um grande desastre para a cultura", um momento em que eles não sabem o que fazer da vida. O Jovem Ngrenhdjam Xikrin faz críticas precisas quanto à dinâmica de comunicação entre o empreendedor e as nove etnias impactadas e pontua os problemas nas áreas de educação e saúde que afligem não só o seu povo, mas também os moradores da cidade de Altamira. Para finalizar, os homens da aldeia Bacajá cobram que os brancos parem (imediatamente) de falar que vão barrar o rio porque isso vai prejudicar seriamente o futuro de seus filhos e netos. Contudo, a construção da barragem continua.

Por todo este leque de contribuições, "Belo Monte e a questão indígena" é um importante registro da situação histórica em que vivemos e dos projetos de futuro que por ora nossos tomadores de decisão desenham para os próximos anos. A consistência das análises vai além da mera documentação do presente e indicam aspectos estruturais, pontos sensíveis e fragilidades do estado de direito no Brasil atual. É possível notar um aspecto comum que perpassa as vinte contribuições que integram o dossiê: a proliferação de expectativas, inseguranças e incertezas que um projeto de desenvolvimento da escala de Belo Monte vem gerando nos âmbitos jurídico, legislativo, tecnopolítico, e, sobretudo, em relação ao futuro dos povos indígenas e tradicionais que vivem na região.

Recebido em: 30/04/2015

Aprovado em: 17/06/2015
Alessandro Roberto Oliveira é Doutor em Antropologia Social pela Universidade de Brasília (UnB) e Professor Adjunto de Antropologia da Universidade Federal de Goiás (UFG). 